\title{
Journal of Bacteriology and

\section{Phylogenetic Grouping of Dominant Fecal Escherichia coli Isolates from Healthy Males and Females in Al-Kut/Wasit Province/Iraq}

\author{
Sareaa MG Al-Mayahie ${ }^{1 *}$, Alaa AM Al-Khafajy ${ }^{1}$, Nuha AS Dosh ${ }^{2}$, Assel RK Al-Rekabi ${ }^{1}$ and Ahlam GN Al-Atabie ${ }^{1}$ \\ ${ }^{1}$ Department of Biology, College of Science, University of Wasit, Wasit, Iraq \\ ${ }^{2}$ Department of Microbiology, College of Medicine, University of Kufa, Kufa, Iraq
}

*Corresponding author: Sareaa MG Al-Mayahie, Department of Biology, College of Science, University of Wasit, Wasit 52004, Iraq, Tel : 096407802833209; E-mail: sareaamaseer@yahoo.com

Rec date: December 07, 2014, Acc date: January 28, 2015, Pub date: February 02, 2015

Copyright: (c) 2015 Sareaa MG Al-Mayahie. This is an open-access article distributed under the terms of the Creative Commons Attribution License, which permits unrestricted use, distribution, and reproduction in any medium, provided the original author and source are credited.

\begin{abstract}
Fecal isolates of Escherichia coli are divided into four main phylogenetic groups designated A, B1, B2 and D. Most commensal strains belong to group $A$ and have fewer virulence factors than the extra intestinal pathogenic $E$. coli strains (ExPEC). This study was mainly designed for phylogenetic grouping of commensal fecal $E$. coli isolates from healthy males and females in Al-Kut City/Wasit Province/Iraq using PCR-based protocols. Also ExPEC's virulence genes were detected among these isolates. Among this study included isolates $(n=205)$, group $A$ was the most common among both females' and males' isolates (68.5\% vs. $63.0 \%$, respectively), followed by groups: B1 ( $15.7 \%$ vs. $22.6 \%$, respectively), D ( $10.7 \%$ vs. $9.5 \%$, respectively), and B2 ( $4.1 \%$ vs. $4.7 \%$, respectively). Gender distribution of phylogenetic groups showed insignificant differences between females and males. Females' and males' isolates did not differ significantly for all of the detected ExPEC's virulence genes, except for papC which was significantly $(P \leq 0.05)$ more prevalent among males' isolates $(16.6 \%)$ than among females' isolates $(6.6 \%)$. In both females' and males' isolates the most prevalent virulence genes were fimH $(97.5 \%$ vs. $100 \%$, respectively) and iucC $(52.0 \%$ vs. $55.9 \%$, respectively), whereas the least prevalent were sfa/foc $(0 \%$ each) and $h l y(0.82 \%$ vs. $0 \%$, respectively). Furthermore, virulence genes were concentrated in isolates clustered in group B2.

In both females and males, high percent of dominant commensal fecal $E$. coli isolates from Iraqi people in Al-Kut City clustered in phylogroup A followed by groups B1 and D whereas group B2 was rare. Also, dominant fecal strains with ExPEC characteristics were much less prevalent.
\end{abstract}

Keywords: Fecal E. coli; Phylogroups; Virulence genes; Males and females

\section{Introduction}

Escherichia coli is a member of the normal intestinal microflora of humans and animals. It is also a common cause of extraintestinal infections both in adults $[1,2]$ and neonates $[3,4]$. The reservoir for these extraintestinal pathogenic E. coli (ExPEC) is the human bowel flora [5-7].

Fecal isolates of E. coli are divided into four main phylogenetic groups (ECOR groups) designated A, B1, B2 and D [8]. These groups differ in their phenotypic and genotypic characteristics [9]. The virulent extraintestinal $E$. coli strains belong mainly to group B2 and, to a lesser extent, to group $\mathrm{D}$, whereas most commensal strains belong to group A [10]. Numerically, group A is the dominant group among normal fecal $E$. coli but relative percent distribution of these groups differs from one country to another $[11,12]$. In comparison with ExPEC, the human commensal fecal strains had fewer virulence factors $[11,13]$. Such VFs induce disease through their ability to help the organisms to avoid or subvert host defenses, colonize key anatomical sites, perturb host physiology, invade host tissues, and/or incite a noxious host inflammatory response [9,13-15].

Worldwide, many studies were carried out for fecal $E$. coli phylogenetic grouping, while here in Iraq little if any are available regarding this subject, therefore; this study was mainly designed for phylogenetic grouping of dominant commensal fecal $E$. coli isolates from healthy males and females in Al-Kut City/Wasit Province/Iraq. The distributions of several known extraintestinal virulence factors (fimH, papC, sfa/foc adhesin-encoding operons, and hly and iucC operons) were also surveyed among this study included isolates.

\section{Methods}

\section{Bacterial isolates}

A total of 205 fecal $E$. coli isolates from adult healthy females $(n=75)$ and males $(n=45)$ aged $18-45$ years, who were not aware of any illness at the time of sampling, were included in this study. The volunteers were college students, college staff, and college staff's family members. From each volunteer an oral consent was obtained to publish this work. This work was approved by the Scientific Committee of the College of Science/ University of Wasit/ Wasit Province/Iraq.

\section{Specimen collection, processing and identification of the isolates}

The specimens were collected during the period December 2008 through June 2010. A single fecal specimen was collected per person and processed according to Plos et al. [16] to obtain dominant fecal.

Bacteria were isolated from freshly deposited feces. Fecal collection was carried out using a swab/transport tube system containing phosphate buffered saline. Bacteria were isolated by dilution-streaking 
Citation: Al-Mayahie SMG, Al-Khafajy AAM, Dosh NAS, Al-Rekabi ARK, Al-Atabie AGN (2015) Phylogenetic Grouping of Dominant Fecal Escherichia coli Isolates from Healthy Males and Females in Al-Kut/Wasit Province/lraq . J Bacteriol Parasitol 6: 215. doi: $10.4172 / 2155-9597.1000215$

Page 2 of 4

the sample (within 1-2 hours after collection) onto an eosine methylene blue (EMB, Himedia, India) agar plate. After incubation, from each plate the last three colonies (with the appropriate color and morphology that is characteristics of E. coli) at the end of the streak area were selected and then subcultured onto a tryptic soy agar (TSA) (Himedia, India) plate. Lactose positive isolates were tested for citrate utilization, and urease and indole production $[17,18]$. All incubations were carried out at $35^{\circ} \mathrm{C}$. For most individuals $1-2$ isolates were included in this study because some isolates were lost during the study period before performing PCR experiments.

\section{Phylogenetic grouping of the isolates}

The isolates were classified by use of the rapid phylogenetic grouping technique described by Clermont et al. [19]. This method is based on a triplex PCR involving the amplification of two genes (chuA and yjaA) and of an anonymous fragment of DNA from E. coli. Briefly, PCR was performed in a total volume of $25 \mu \mathrm{l}$ containing 12.5 $\mu \mathrm{l}$ of KapaTaq 2x Ready Mix (KAPA Biosystems, USA), 20 pmol concentrations of each primer, and $5 \mu$ of DNA template. The PCR conditions were as follows: denaturation for $4 \mathrm{~min}$ at $94^{\circ} \mathrm{C}, 30$ cycles of $5 \mathrm{~s}$ at $94^{\circ} \mathrm{C}$ and $10 \mathrm{~s}$ at $59^{\circ} \mathrm{C}$, and a final extension step of $5 \mathrm{~min}$ at $72^{\circ} \mathrm{C}$. The results were interpreted as follows, according to Clermont et al. [19]: group $\mathrm{B} 2$ (chuA+, yjaA+, TspE.C2 \pm ), group $\mathrm{D}(\mathrm{chuA}+$, yjaA-, TspE.C2 \pm ), group B1 (chuA-, yjaA \pm , TspEC2+) and group A (chuA-, yjaAt, TspE.C2-).

\section{Genotypic virulence characterization of the isolates}

Multiplex PCR was used to detect five genes encoding virulence determinants usually associated with ExPEC: fimH (type 1 pili), papC (type P pili), sfa/foc (type S pili and type 1C fimbriae), hly (alphahemolysin), and iucC (aerobactin) [13,20]. Virulence factor genes were amplified according to Johnson and Stell (10) and Yamamoto et al. [21] with the primers described elsewhere [10,21-23] in a total volume of $50 \mu$ l containing $25 \mu \mathrm{l}$ of KapaTaq 2x Ready Mix (KAPA Biosystems, USA), 20 pmol concentrations of each primer except hly $(30 \mathrm{pmol})$, and $5 \mu \mathrm{l}$ of DNA template. The reaction conditions were as follows: initial denaturation at $94^{\circ} \mathrm{C}$ for $5 \mathrm{~min}$ followed by 25 cycles of denaturation at $94^{\circ} \mathrm{C}$ for $30 \mathrm{~s}$, annealing at $63^{\circ} \mathrm{C}$ for $30 \mathrm{~s}$, and extension at $68^{\circ} \mathrm{C}$ for $3 \mathrm{~min}$, followed by a final $10 \mathrm{~min}$ extension period at $72^{\circ} \mathrm{C}$. The amplification products were separated by electrophoresis in a $2 \%$ agarose gel containing ethidium bromide. A 100-bp DNA ladder (Kappa Universal, USA) was used in each gel as a molecular size marker.

\section{Statistical analysis}

Differences in the distributions of the studied determinants were tested by Chi square [24]. A P value of $\leq 0.05$ was considered to indicate statistical significance.

\section{Results}

Among all this study included isolates $(\mathrm{n}=205)$, the most commonly detected phylogenetic group was group A (66.3\%) (Table 1), followed by groups: B1 (18.5\%), D (10.2\%), and B2 (4.3\%). Gender distribution of phylogenetic groups showed insignificant differences between females and males.

Females' and males' isolates did not differ significantly for all of the ExPEC's virulence genes detected here in this study, except for papC which was significantly $(\mathrm{P} \leq 0.05)$ more prevalent among males' isolates $(16.6 \%)$ than among females' isolates (6.6\%) (Table 2). Among both females' and males' isolates the most prevalent genes were fim $H$ $(97.5 \%$ vs. $100 \%$, respectively) and iucC $(52.0 \%$ vs. $55.9 \%$, respectively), whereas the least prevalent genes were $s f a / f o c$ ( $0 \%$ each) and $h l y(0.82 \%$ vs. $0 \%$, respectively $)$.

\begin{tabular}{|l|l|l|l|l|l|}
\hline \multicolumn{2}{|l|}{ Study individuals } & \multicolumn{2}{l}{$\begin{array}{l}\text { No. (\%) of isolates positive for the indicated } \\
\text { phylogroup }\end{array}$} \\
\hline Gender & $\begin{array}{l}\text { No. of E. } \\
\text { coli } \\
\text { isolates }\end{array}$ & A & B1 & B2 & D \\
\hline Females & 121 & $83(68.5)$ & $19(15.7)$ & $5(4.1)$ & $13(10.7)$ \\
\hline Males & 84 & $53(63.0)$ & $19(22.6)$ & $4(4.7)$ & $8(9.5)$ \\
\hline Total & 205 & $136(66.3)$ & $38(18.5)$ & $9(4.3)$ & $21(10.2)$ \\
\hline
\end{tabular}

Table 1: Distribution of phylogenetic groups among fecal E. coli isolates from healthy males and females.

\begin{tabular}{|l|l|l|l|}
\hline \multirow{2}{*}{ ExPEC VFs' gene } & \multicolumn{3}{|l|}{ No. (\%) of isolates positive for the indicated trait } \\
\cline { 2 - 4 } & $\begin{array}{l}\text { Females' isolates } \\
(\mathrm{n}=121)\end{array}$ & $\begin{array}{l}\text { Males' isolates } \\
(\mathrm{n}=84)\end{array}$ & Total $(\mathrm{n}=205)$ \\
\hline fimH & $118(97.5)$ & $84(100)$ & $202(98.5)$ \\
\hline papC & $8(6.6)$ & $14(16.6)$ & $22(10.7)$ \\
\hline sfa/foc & 0 & 0 & 0 \\
\hline hly & $1(0.82)$ & 0 & $1(0.48)$ \\
\hline iucC & $63(52.0)$ & $47(55.9)$ & $110(53.6)$ \\
\hline
\end{tabular}

Table 2: Prevalence of ExPEC virulence genes among fecal E. coli isolates from healthy males and females.

Phylogenetic distribution of virulence genes was summarized in Table 3. In both females and males virulence genes were concentrated in isolates clustered in group B2, among which the highest rates of multiple virulence factors possession (three or more virulence factors/ isolate) were demonstrated in both females' (3/5:60.0\%) and males' isolates (2/4:50.0\%), whereas only $15.3 \%$ vs. $12.5 \%$, respectively, $2.4 \%$ vs. $16.9 \%$ and $0 \%$ each of isolates belonged to groups $\mathrm{D}, \mathrm{A}$, and $\mathrm{B} 1$, respectively, had multiple virulence factors.

\section{Discussion}

The vast majority of both females' and males' isolates included in this study clustered in group A (68.5\% vs. 63.0\%, respectively) (Table $1)$, whereas isolates clustered in group B2 were the least prevalent ( $4.1 \%$ vs. $4.7 \%$, respectively). Gender distribution of phylogroups showed insignificant differences between females and males. Similar results were obtained by others $[25,26]$ who found that sex and age factors had no effect on distribution of phylogroups. Whereas Gordon et al. [27] found that in males the probability of isolating A or D strains increased with host age, whilst the probability of detecting a group B2 strain declined, while in females the probability of recovering $\mathrm{A}$ or B2 strains increased with increasing host age and there was a concomitant decline in the likelihood of isolating B1 or D strains. The reason for these differences may lie in that Gordon et al. [27] had used 
Citation: Al-Mayahie SMG, Al-Khafajy AAM, Dosh NAS, Al-Rekabi ARK, Al-Atabie AGN (2015) Phylogenetic Grouping of Dominant Fecal Escherichia coli Isolates from Healthy Males and Females in Al-Kut/Wasit Province/lraq . J Bacteriol Parasitol 6: 215. doi: $10.4172 / 2155-9597.1000215$

Page 3 of 4

fecal isolates from patients suffering from gastroenteritis, whereas, our isolates were from healthy volunteers who were not aware of any symptoms at the time of sampling. Also these researchers' study included a wider age range (0-80 years), while our study included only young ages (18-45 years).

\begin{tabular}{|c|c|c|c|c|c|c|}
\hline \multirow[t]{2}{*}{ Isolates } & \multirow{2}{*}{$\begin{array}{l}\text { Phylogroups } \\
\text { (No. of isolates) }\end{array}$} & \multicolumn{5}{|c|}{ No. $(\%)$ of isolates positive for the indicated virulence gene } \\
\hline & & $\mathrm{fimH}$ & papC & $s f a / f o c$ & hly & iucC \\
\hline \multirow{4}{*}{$\begin{array}{l}\text { Females' isolates } \\
(n=121)\end{array}$} & $A(83)$ & $80(96.3)$ & $2(2.4)$ & 0 & 0 & $35(42.1)$ \\
\hline & B1 (19) & $19(100)$ & 0 & 0 & 0 & $12(63.1)$ \\
\hline & B2 (5) & $5(100)$ & $3(60.0)$ & 0 & $1(20.0)$ & $5(100)$ \\
\hline & $\mathrm{D}(14)$ & $14(100)$ & $3(21.4)$ & 0 & 0 & $11(78.5)$ \\
\hline \multirow{4}{*}{$\begin{array}{l}\text { Males' isolates } \\
(n=84)\end{array}$} & A (53) & $53(100)$ & $10(18.8)$ & 0 & 0 & $35(66.0)$ \\
\hline & B1 (19) & $19(100)$ & 0 & 0 & 0 & $6(31.5)$ \\
\hline & B2 (4) & $4(100)$ & $3(75.0)$ & 0 & 0 & $3(75.0)$ \\
\hline & $\mathrm{D}(7)$ & $7(100)$ & 1 (14.2) & 0 & 0 & $3(42.8)$ \\
\hline \multirow{4}{*}{$\begin{array}{l}\text { Total } \\
(n=205)\end{array}$} & $A(136)$ & $133(97.7)$ & $12(8.8)$ & 0 & 0 & $70(51.4)$ \\
\hline & B1 (38) & $38(100)$ & 0 & 0 & 0 & $18(47.3)$ \\
\hline & B2 (9) & $9(100)$ & $6(66.6)$ & 0 & $1(11.1)$ & $8(88.8)$ \\
\hline & $D(21)$ & $21(100)$ & $4(19.0)$ & 0 & 0 & $14(66.6)$ \\
\hline
\end{tabular}

Table 3: Phylogenetic distribution of virulence genes among fecal $E$. coli isolates from healthy males and females.

As a whole, this study results were consistent with those obtained by Duriez et al. [11] and $\mathrm{Li}$ et al. [26] who found that strains from phylogenetic groups A and B1 were the most common, followed by phylogenetic group D strains, while strains of the phylogenetic group B2 were rare. This study isolates were dominated by group A $(66.3 \%)$, as it was shown in previous studies $[28,29]$ that the E. coli clonal community of a person is numerically dominated by one strain, or at most a few strains. Other researchers $[13,27,30]$ found much more prevalence of phylogroup B2 among fecal isolates in comparison with this study results. This confirmed the fact that human $E$. coli commensal microbiota varied in a population-specific manner as the geographic locations of the human populations seem to play an important role in structuring the E. coli populations [25]. So that, it seems likely that geographic and climatic factors play an important role in structuring the E. coli population, worldwide. In addition to the effects of diet and food processing differences between nations. Also, these differences may reflect the influence of host genetic on the commensal flora $[11,25,26,31,32]$. Therefore, the distribution of phylogenetic groups, subgroups and genetic markers is non-random in the hosts [33] and the four E. coli groups may differ in their ecological niches and life-history characteristics [34].

The most commonly detected virulence genes among this study included isolates were fimH (98.5\%) and iucC (53.6\%), whereas the least detected genes were $s f a / f o c(0 \%)$ and hly $(0.48 \%)$. Females' and males' isolates did not differ significantly for all of the virulence genes detected here in this study, except for papC which was significantly ( $\mathrm{P}$ $\leq 0.05)$ more prevalent among males' isolates $(16.6 \%)$ than among females' isolates $(6.6 \%)$ (Table 2). The exact reason for this difference was not clear, but it may reflect the morphological, physiological, and dietary differences in the intestinal tract of males and females which influence the distribution of $E$. coli genotypes as the intestinal tract of males and females appear to represent different environments for $E$. coli [27].

Phylogenetic distribution of virulence genes (Table 3) revealed that in both females and males virulence genes were concentrated in isolates clustered in group B2, while isolates clustered in groups D, A, and $\mathrm{B} 1$ had the least prevalence of virulence genes. Our results were in agreement with what is known that the human commensal strains had fewer virulence factors than the extraintestinal pathogenic strains $[11,13]$. In addition, the concentration of virulence factors (two or three virulence factors per strain) was in isolates belonged to group B2 which indicated the influence of phylogenetic origin of an isolate in determining its virulence $[11,13]$.

\section{Conclusions}

In both males and females, commensal fecal $E$. coli isolates from Iraqi people in Al-Kut city were dominated by phylogroup A followed by groups B1 and D, whereas group B2 was rare. Also, dominant fecal strains with ExPEC characteristics were much less prevalent.

\section{Acknowledgments}

We are grateful to the college of Science/University of Wasit for supporting this research.

\section{References}

1. Zhang L, Fozman B, Marrs C (2002) Both urinary and rectal Escherichia coli isolates are dominated by strains of phylogenetic group B2. J Clin Microbiol 40: 3951-3955.

2. Gillespie SH, Hawkey PM (2006) Principles and Practical Clinical Bacteriology. (2ndedn), John Wiley \& Sons, Ltd, London. 
Citation: Al-Mayahie SMG, Al-Khafajy AAM, Dosh NAS, Al-Rekabi ARK, Al-Atabie AGN (2015) Phylogenetic Grouping of Dominant Fecal Escherichia coli Isolates from Healthy Males and Females in Al-Kut/Wasit Province/lraq . J Bacteriol Parasitol 6: 215. doi: $10.4172 / 2155-9597.1000215$

Page 4 of 4

3. Watt S, Lanotte P, Mereghetti L, Moulin-Schouleur M, Picard B, et al. (2003) Eschierichia coli strain from pregnant women and neonates: intraspecies genetic distribution and prevalence of virulence factors. J Clin Microbiol 41: 1929-1935.

4. Schmidt H, Hensel M (2004) Pathogenicity islands in bacterial pathogenesis. Clin Microbiol Rev 17: 14-56.

5. Krohn MA, Soe TS, Rabe LK, Brown Z, Hillier SL (1997) Vaginal colonization by Escherichia coli as a risk for very low birth weight delivery and other perinatal complications. J Infec Dis 175: 606-610.

6. Kunin CM (1997) Urinary tract infections: Detection, prevention and management. (5thedn), Williams \& Wilkins, Baltimore.

7. Mulvey MA (2002) Adhesion and Entry of Uropathogenic Escherichia coli. Cell Microbiol 4: 257-271.

8. Herzer PJ, Inouye S, Inouye M, Whittam TS (1990) Phylogenetic distribution of branched RNA-linked multicopy single stranded DNA among natural isolates of Escherichia coli. J Bacteriol 172: 6175-6181.

9. Johnson JR, Delavari P, Kuskowski M, Stell AL (2001) Phylogenetic distribution of extraintestinal virulence-associated traits in Escherichia coli. J Infect Dis 183: 78-88.

10. Johnson JR, Stell AL (2000) Extended virulence genotypes of Escherichia coli strains from patients with urosepsis in relation to phylogeny and host compromise. J Infect Dis 181: 261-272.

11. Duriez P, Clermont O, Bonacorsi S, Bingen E, Chaventre A, et al. (2001) Commensal Escherichia coli are phylogentically distributed among geographically distinct human populations. Microbiol 147: 1671-1676.

12. Obata-Yasuka M, Ba-Thein W, Tsukamoto T, Yoshikawa $\mathrm{H}$, Hayashi $\mathrm{H}$ (2002) Vaginal Escherichia coli share common virulence factor profiles, serotypes and phylogeny with other extraintestinal E. coli. Microbiol 148: 2745-2752.

13. Johnson JR, Owens K, Gajewski A, Kuskowski MA (2005) Bacterial characteristics in relation to clinical source of Escherichia coli isolates from women with acute cystitis or pyelonephritis and uninfected women. J Clin Microbiol 43: 6064-6072.

14. Johnson JR (1991) Virulence factors in Escherichia coli urinary tract infection. Clin Microbiol Rev 4: 80-128.

15. Wiles TJ, Kulesus RR, Mulvey MA (2008) Origins and virulence mechanisms of uropathogenic Escherichia coli. Exp Mol Pathol 85: 11-19.

16. Plos K, Connell H, Jodal U, Marklund BI, Mårild S, et al. (1995) Intestinal carriage of $\mathrm{P}$ fimbriated Escherichia coli and the susceptibility to urinary tract infection in young children. J Infect Dis 171: 625-631.

17. MacFaddin JF (2000) Biochemical tests for identification of medical bacteria. (3rdedn), Lippincott Williams and Wilkins, London.

18. Forbes BA, Sahm DF, Weissfeld AS (2002) Bailey \& Scott's Diagnostic Microbiology. (11thedn), Mosby, USA.

19. Clermont O, Bonacorsi S, Bingen E (2000) Rapid and simple determination of Escherichia coli phylogenetic group. Appl Environ Microbiol 66: 4555-4558.

20. Lane MC, Mobley HLT (2007) Role of P-fimbrial-mediated adherence in pyelonephritis and persistence of uropathogenic Escherichia coli (UPEC) in the mammalian kidney. Kidney International 72: 19-25.
21. Yamamoto S, Terai A, Yuri K, Kurazono H, Takeda Y, et al. (1995) Detection of urovirulence factors in Escherichia coli by multiplex polymerase chain reaction. FEMS Immunol Med Microbiol 12: 85-90.

22. Le Bouguenec C, Archambaud M, Labigne A (1992) Rapid and specific detection of the pap, afa, and sfa adhesin-encoding operon in uropathogenic Escherichia coli strains by polymerase chain reaction. J Clin Microbiol 30: 1189-1193.

23. Bingen E, Bonacorsi S, Brahimi N, Denamur E and Elion J (1997) Virulence patterns of Escherichia coli K1 strains associated with neonatal meningitis. J Clin Microbiol 35: 2981-2982.

24. Ross SM (2009) Introduction to probability and statistics for Engineers and Scientists. (4thedn), Elsevier, London.

25. Escobar-Pa'ramo P, Grenet K, Le Menac A, Rode L, Salgado E, et al. (2004) Large-scale population structure of human commensal Escherichia coli isolates. Appl Environ Microbiol 70: 5698-5700.

26. Li B, Sun JY, Han LZ, Huang XH, Fu Q, et al. (2010) Phylogenetic groups and pathogenicity island markers in fecal Escherichia coli isolates from asymptomatic humans in China. Appl Environ Microbiol 76: 6698-6700.

27. Gordon DM, Stern SE, Collignon PJ (2005) Influence of the age and sex of human hosts on the distribution of Escherichia coli ECOR groups and virulence traits. Microbiol 151: 15-23.

28. Gordon DM, Bauer S, Johnson JR (2002) The genetic structure of Escherichia coli populations in primary and secondary habitats. Microbiol 148: 1513-1522.

29. Schlager TA, Hendley JO, Bell AL, Whittman TS (2002) Clonal diversity of Escherichia coli colonizing stools and urinary tracts of young girls. Infect Immun 70: 1225-1229.

30. Jakobsen L, Spangholm DJ, Skjøt-Rasmussen L, Porsbo LJ, Olsen KEP, et al. (2008) Comparison of phylogroups and virulence genes of Escherichia coli obtained from healthy humans and patients with urinary tract infection in Denmark. European Society of Clinical Microbiology and Infectious Diseases.

31. Unno T, Han D, Jang J, Lee SN, Ko G, et al. (2009) Absence of Escherichia coli phylogenetic group B2 strains in humans and domesticated animals from Jeonnam Province, Republic of Korea. Appl Environ Microbiol 75: 5659-5666.

32. Lee S, Yu JK, Park K, Oh EJ, Kim SY, et al. (2010) Phylogenetic groups and virulence factors in pathogenic and commensal strains of Escherichia coli and their association with blaCTX-M. Ann Clin Lab Sci Autum 40: 361-367.

33. Carlos C, Pires MM, Stoppe NC, Hachich EM, Sato MIZ, et al. (2010) Escherichia coli phylogenetic group determination and its application in the identification of the major animal source of faecal contamination. BMC Microbiol 10: 161

34. Gordon DM, Cowling A (2003) The distribution and genetic structure of Escherichia coli in Australian vertebrates: host and geographic effects. Microbiol 149: 3575-3586.

35. Russo TA, Johnson JR (2000) Proposal for a new inclusive designation for extraintestinal pathogenic isolates of Escherichia coli: ExPEC. J Infect Dis 181: 1753-1754. 